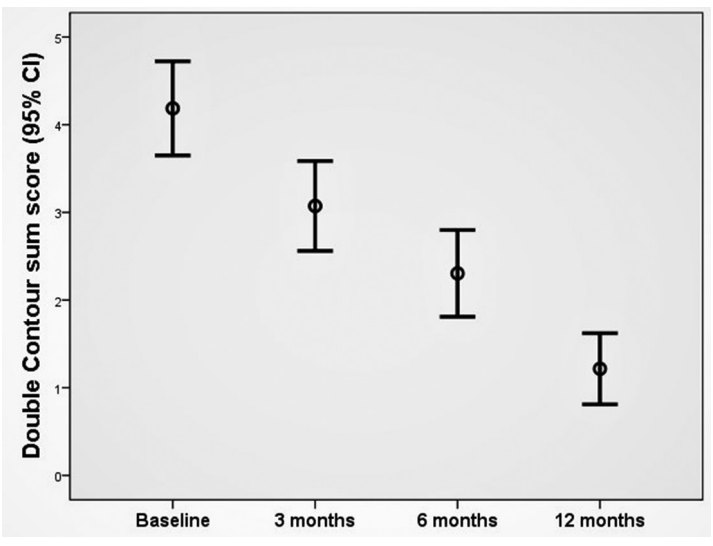

Abstract OP0211 - Table 1

\begin{tabular}{|c|c|c|c|c|}
\hline & $\begin{array}{c}\text { Baseline } \\
(n=161) \\
\text { Mean (SD) }\end{array}$ & $\begin{array}{c}3 \text { months } \\
(n=124) \\
\text { Mean (SD) }\end{array}$ & $\begin{array}{c}6 \text { months } \\
(n=115) \\
\text { Mean (SD) }\end{array}$ & $\begin{array}{c}12 \text { months } \\
(n=88) \\
\text { Mean (SD) }\end{array}$ \\
\hline Double Contour score & $4.2(3.4)$ & $3.1(2.8)^{\star \star}$ & $2.3(2.7)^{\star *}$ & $1.2(1.9)^{\star *}$ \\
\hline Tophi score & $6.5(6.6)$ & $6.3(5.7)$ & $5.4(6.1)^{\star *}$ & $4.2(5.3)^{\star *}$ \\
\hline Aggregates score & $9.1(5.3)$ & $8.8(4.9)^{\star}$ & $7.9(5.2)^{\star *}$ & $6.7(4.9)^{* *}$ \\
\hline $\begin{array}{l}\text { Double Contour, tophi and } \\
\text { aggregates sum score }\end{array}$ & $19.8(13.6)$ & $\underset{* *}{18.1(12.0)}$ & $\underset{* \star}{15.6(12.8)}$ & $12.1(10.9)^{\star \star}$ \\
\hline
\end{tabular}

Conclusions: During a treat-to-target approach with ULT all deposits decreased, and most extensively for DC. This study shows that reduction of the uric acid load in gout during treat-to-target ULT can be visualised by US, and that DC may be the most sensitive to change.

Disclosure of Interest: None declared

DOI: 10.1136/annrheumdis-2018-eular.3250

\section{OP0212 MOBILE PHONE TEXT MESSAGES FOR IMPROVING ALLOPURINOL ADHERENCE: A RANDOMISED CONTROLLED TRIAL OF TEXT MESSAGE REMINDERS}

K. Bunphong, P. Narongroeknawin. Internal Medicine, Phramongkutklao Hospital, Bangkok, Thailand

Background: Medication adherence is important to treatment success, particularly in gout where the target level achievement is critical. However, there is no evidence that mobile phone text message reminder is effective in improving treatment adherence and clinical outcomes for gout.

Objectives: To evaluate the effect of mobile phone text messaging on the adherence to allopurinol treatment and serum uric acid (SUA) level of patient with gout in a randomized-controlled trial.

Methods: Adult patients who were diagnosed of gout by 1977 ARA classification criteria for gout, receiving at least 1 month of allopurinol, and had estimated glomerular filtration rate greater than $30 \mathrm{~mL} / \mathrm{min} / 1.73 \mathrm{~m}^{2}$ were enrolled and randomly assigned to 2 groups by block randomization. Patients in the intervention group received a daily short message reminder to take allopurinol for 90 days. Patients in the control group received a weekly short message information about non-pharmacologic treatment for gout in plain language. The primary outcomes were allopurinol adherence, defined as the Medication Taking Behaviour for Thai patient (MTB-Thai) score $>21$, and SUA level at 12 weeks. The primary analysis was by intention-to-treat. This trial is registered with Thai Clinical Trials Registry, TCTR20171229004.

Results: Eighty-two patients were randomised, with 42 in the intervention group and 40 in the control group. No significant different of baseline characteristic, SUA $(7.66 \pm 1.24$ vs $7.78 \pm 1.17 \mathrm{mg} / \mathrm{dL})$ and MTB-Thai score $(18.38 \pm 0.73$ vs 18.37 $\pm 0.95)$ between two groups. At week 12,37 patients $(88.1 \%)$ in the intervention group achieved adherence compared with none of patient in the control group (RR for adherence $71.5,95 \% \mathrm{Cl}: 4.54$ to $1126.80 ; \mathrm{p}=0.002$ ). SUA level was decreased significantly from baseline in both study groups, however, the reduction in the intervention group was significantly greater than in the control group $(-1.47 \pm 0.86$ vs $-0.28 \pm 0.39 \mathrm{mg} / \mathrm{dL}, \mathrm{p}<0.001)$. Serum creatinine was significantly decreased in the intervention group $(-0.03 \pm 0.09 \mathrm{mg} / \mathrm{dL}, \mathrm{p}<0.031)$, while serum creatinine was unchanged in the control group $(0.01 \pm 0.08 \mathrm{mg} / \mathrm{dL}, \mathrm{p}=0.84)$.

Conclusions: Patients who received daily short message reminder had significantly improved adherence and reduction in SUA compared with the control individuals. Mobile phones text reminders may be an important tool to enhance allopurinol adherence and help in controlling SUA level in gout patients.

Disclosure of Interest: None declared

DOI: 10.1136/annrheumdis-2018-eular.2251

\section{THURSDAY, 14 JUNE 2018 'Why does BMI matter?'}

\section{OP0213 WHAT IS THE IMPACT OF POOR PROGNOSTIC FACTORS ON THE ACHIEVEMENT OF LOW DISEASE ACTIVITY OR REMISSION IN PATIENTS WITH RHEUMATOID ARTHRITIS?}

L. Baganz ${ }^{1}$, A. Richter ${ }^{1,2}$, K. Albrecht $^{1}$, M. Schneider ${ }^{3}$, G.-R. Burmester ${ }^{4}$, A. Zink ${ }^{1,4}$ A. Strangfeld $1 .{ }^{1}$ German Rheumatism Research Center, Berlin; ${ }^{2}$ Institute for Community Medicine, Greifswald; ${ }^{3}$ Heinrich-Heine-University, Düsseldorf, ${ }^{4}$ Charité University Medicine, Berlin, Germany

Background: Poor prognostic factors were initially developed using radiologic progression as outcome. In the 2016 update of the EULAR recommendations it is proposed to use these factors for decision whether or not a biologic should be started.' However, the treatment target is not radiologic progression but low dis ease activity (LDA) or remission.

Objectives: To investigate the impact of indicators of unfavourable prognosis on the achievement of LDA and remission in patients with RA.

Methods: Patients from the German biologics register RABBIT switching from 1 st to 2nd csDMARD were studied. High disease activity (DAS28 >5.1), autoantibodies (RF/ACPA positive), prevalent erosions, functional limitation ( $\mathrm{HAQ} \geq 1.2)$, comorbidities $(\geq 2)$, obesity $\left(\mathrm{BMI}>30 \mathrm{~kg} / \mathrm{m}^{2}\right)$, and smoking were evaluated as prognostic factors. Generalised regression analyses were applied to investigate the role of prognostic factors regarding the achievement of LDA (DAS28 <3.2) or remission (DAS28 <2.6). Receiver operating characteristic $(\mathrm{ROC})$ curves were calculated to compare the ability of the prognostic factors (baseline values) to discriminate patients achieving LDA from those maintaining moderate or high disease activity within six months. The prognostic value of all factors was determined by the area under the ROC curve (AUC).

Results: A total of 1613 patients were studied (mean age 58.9 years, mean disease duration 4.8 years). $35 \%$ had DAS $28>5.1,60 \%$ were RF/ACPA positive, $27 \%$ had erosions, $44 \%$ functional limitation, $37 \%>2$ comorbidities, $32 \%$ were obese, and $26 \%$ current smokers. LDA was achieved by $33 \%$ of patients with DAS28 $>5.1$, by $30 \%$ if also autoantibodies and erosions were present, and by $20 \%$ if DAS28 $>5.1, \mathrm{HAQ} \geq 1.2, \geq 2$ comorbidities and obesity were present. DAS28 $>5.1$ (OR 0.41 [95\% Cl: 0.32 to 0.52$]$ ), $\mathrm{HAQ}>1.2(0.58[0.46 ; 0.74]), \geq 2$ comorbidities (0.66 [0.47 to 0.90$])$ and obesity $(0.72[0.57 ; 0.91])$ independently decreased the probability of LDA within six months. Current smoking $(0.67$ [0.48;0.93] was negatively associated with remission. RF/ACPA and erosions were not associated. The ROC curves for achieving LDA for the significant factors (DAS28 $>5.1, \mathrm{HAQ} \geq 1.2, \geq 2$ comorbidities and obesity) and a model containing only these four factors are shown in figure $1(\mathrm{a})$. The AUC of the model is higher than the one of the single curves. The AUC for the full model (figure 1(b)) which was additionally adjusted for age, sex, autoantibodies, erosions, current smoking, therapy and time is similar to the one of the reduced model.
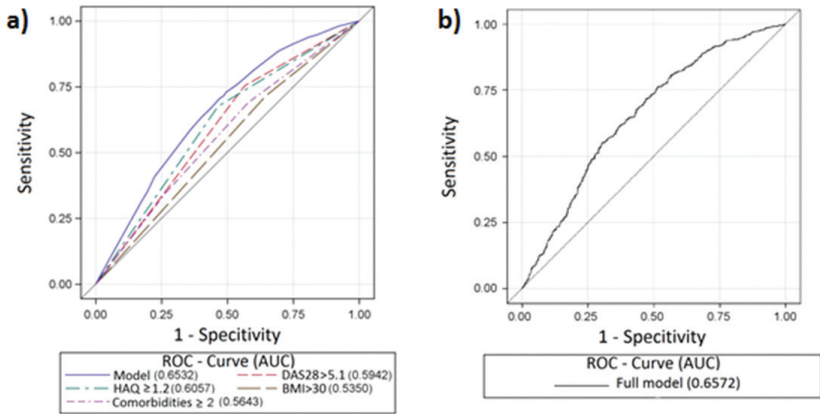

Conclusions: High disease activity, functional limitation, comorbidities and obesity had significant negative impact on LDA and remission. They should be considered as poor prognostic factors in csDMARD-treated patients. It appears that a combination of the factors is better than using single ones. 
REFERENCES:

[1] Smolen JS, et al. Ann Rheum Dis 2017;76:960-977.

[2] Smolen JS, Landewé R, Bijlsma J, et al. EULAR recommendations for the management of rheumatoid arthritis with synthetic and biological diseasemodifying antirheumatic drugs: 2016 update. Ann Rheum Dis 2017;76:960-977.

Acknowledgements: RABBIT is supported by a joint, unconditional grant from AbbVie, Bristol-Myers Squibb, Celltrion, Hexal, Lilly, MSD Sharp and Dohme, Pfizer, Roche, Samsung Bioepis, Sanofi und UCB.

Disclosure of Interest: L. Baganz: None declared, A. Richter: None declared, K. Albrecht: None declared, M. Schneider Grant/research support from: Abbvie, Chugai, UCB, Consultant for: Abbvie, Astra-Zeneca, BMS, Chugai, GSK, Lilly, MSD, Mundipharma, Pfizer, Roche, UCB, G.-R. Burmester Consultant for: AbbVie, BMS, Lilly, MSD, Pfizer, Roche, UCB, A. Zink Speakers bureau: BMS, Lilly, Pfizer, Roche, UCB, A. Strangfeld Speakers bureau: AbbVie, BMS, Lilly, MSD, Pfizer, Roche, UCB

DOI: 10.1136/annrheumdis-2018-eular.4564

\section{OP0214 BASELINE COMORBIDITIES AND OVERWEIGHT PREDICT FUNCTIONAL STATUS AND HEALTH- RELATED QUALITY OF LIFE 9 YEARS LATER - A LONGITUDINAL COHORT STUDY OF 428 PATIENTS WITH RHEUMATOID ARTHRITISRECEIVING STANDARD CARE}

L. Linde ${ }^{1}$, M.L. Hetland ${ }^{2} .{ }^{1}$ Center for Rheumatology and Spine Diseases; ${ }^{2}$ DANBIO, Center for Rheumatology and Spine Diseases, Rigshospitalet, Copenhagen, Denmark

Background: Health-related quality of life (HRQOL) and functional status are markedly reduced in patients with rheumatoid arthritis (RA) leading to a significant societal and individual burden. Comorbidities and sociodemographic factors are associated with reduced HRQOL and functional status in cross-sectional studies of RA, ${ }^{1}$ but their predictive value is largely unknown as longitudinal studies are lacking.

Objectives: To investigate whether comorbidities and sociodemographic factors predict $\mathrm{HRQOL}$ and functional status 9 years later in real-world patients with RA.

Methods: Consecutive patients with RA were recruited from a university hospital outpatient clinic between ${ }^{\text {Juy } 2006}$ and July 2007. Data regarding sex, age, disease duration, disease activity score of 28 joints and CRP (DAS28), number of comorbid conditions, marital status (married/cohabiting vs living alone), smoking (ever, previously or currently), exercise ( $\geq$ once a week vs not regularly), body mass index (BMI), educational level (elementary, training or higher), functional status (the health assessment questionnaire (HAQ)) and HRQOL (Euroqol 5 dimensions (EQ-5D)) were registered in the clinical database DANBIO; patients then continued routine care.

EQ-5D includes 5 dimensions of health (mobility, self-care, usual activities, pain/ discomfort, anxiety/depression), each divided into three levels of severity, yielding 243 possible health states. A validated algorithm converts each health state into an index score between 0 (death) and 1 (perfect health). ${ }^{2}$

$\mathrm{HAQ}$ and EQ-5D scores at the most recent follow-up visit were retrieved from DANBIO on Sept 30th 2017. Two linear regression models were built with scores for $\mathrm{HAQ}$ and $\mathrm{EQ}-5 \mathrm{D}$ at follow-up as outcomes, respectively, all baseline variables were entered as possible explanatory variables and stepwise backward selection was employed. Sex, age, disease duration and baseline HAQ/EQ-5D were forced into the models.

Results: 564 patients with RA were recruited ( $81 \%$ women, median (IQR) age: $60^{49-68}$ years, disease duration: 7 (3-16) years, DAS28: 2.9 (2.1-3.7), HAQ: 0.63 (0.25-1.25), EQ-5D: $0.74(0.66-0.82)$ and followed in routine care for a median of $9^{4-10}$ years. 428 and 256 patients had complete $\mathrm{HAQ}$ and EQ-5D scores, respectively at follow-up (HAQ: $0.75(0.25-1.4)$, EQ-5D: $0.78(0.69-0.86)$ ). Patients without complete $\mathrm{HAQ}$ and $\mathrm{EQ}-5 \mathrm{D}$ scores at follow-up were older at baseline (10 and 6 years, respectively, $p<0.0001$ ), while sex, disease duration, DAS28, HAQ and EQ-5D scores were similar.

High HAQ, BMI $26-30 \mathrm{~kg} / \mathrm{m} 2$, and 3 or more comorbid conditions at inclusion were all independently associated with poorer functional status and low EQ-5D 9 years later (table 1). The models with $\mathrm{HAQ}$ or EQ-5D as outcome explained $51 \%$ and $31 \%$ of the variation $\left(\operatorname{Adj} R^{2}\right.$ ), respectively.
Abstract OP0214 - Table 1 Multivariable linear regression model with $\mathrm{HAQ}$ and EQ-5D at follow-up as outcomes.

\begin{tabular}{|c|c|c|c|c|c|c|}
\hline \multirow{3}{*}{$\begin{array}{l}\text { Explanatory variables } \\
\text { Women }\end{array}$} & \multicolumn{3}{|c|}{ HAQ at follow up } & \multicolumn{3}{|c|}{ EQ-5D at follow up } \\
\hline & Coefficient & $95 \%$ & & Coefficient & $95 \%$ & $\mathrm{CI}$ \\
\hline & 0.19 & 0.06 & 0.33 & -0.03 & -0.08 & 0.02 \\
\hline Age (50-75 yrs) & 0.06 & -0.05 & 0.18 & 0.03 & -0.01 & 0.07 \\
\hline Age(>75 yrs) & 0.03 & -0.22 & 0.28 & 0.01 & -0.10 & 0.11 \\
\hline Disease duration (3-10 yrs) & 0.10 & -0.03 & 0.23 & -0.01 & -0.06 & 0.04 \\
\hline Disease duration ( $>10$ yxs $)$ & 0.12 & -0.02 & 0.25 & -0.02 & -0.07 & 0.03 \\
\hline Baseline HAQ (per unit increase) & 0.72 & 0.63 & 0.81 & -0.10 & -0.14 & -0.05 \\
\hline Baseline EQ-5D (per unit increase) & NS & - & - & 0.13 & -0.05 & 0.30 \\
\hline $\mathrm{BMI}\left(<18,5 \mathrm{~kg} / \mathrm{m}^{2}\right)$ & 0.27 & -0.08 & 0.62 & -0.09 & -0.23 & 0.04 \\
\hline BMI $\left(26-30 \mathrm{~kg} / \mathrm{m}^{2}\right)$ & 0.22 & 0.10 & 0.33 & -0.09 & -0.13 & -0.04 \\
\hline $\mathrm{BMI}\left(>30 \mathrm{~kg} / \mathrm{m}^{2}\right)$ & 0.16 & 0.01 & 0.32 & -0.03 & -0.08 & 0.03 \\
\hline One comorbid condition & 0.13 & 0.01 & 0.26 & -0.02 & -0.07 & 0.02 \\
\hline Two comorbid conditions & -0.03 & -0.18 & 0.12 & 0.03 & -0.03 & 0.08 \\
\hline$\geq 3$ comorbid conditions & 0.30 & 0.14 & 0.47 & -0.14 & -0.20 & -0.08 \\
\hline Constant & 0.39 & 0.07 & 0.72 & 0.79 & 0.64 & 0.94 \\
\hline
\end{tabular}

Conclusions: Potentially modifiable factors (overweight and comorbidities) were independently and consistently associated with worse functional status and HRQOL at follow-up 9 years later in patients with RA receiving standard care. The findings suggest that focus on lifestyle and comorbidities in patients with RA may improve important long-term outcomes.

REFERENCES:

[1] Linde L, et al. J Rheumatol 2009;36(10):2183-2189.

[2] Wittrup-Jensen K, et al. Scand J Public Health 2009;00:1-8.

Disclosure of Interest: None declared

DOI: 10.1136/annrheumdis-2018-eular.2098

THURSDAY, 14 JUNE 2018

Musculoskeletal pain; feeding the opioid epidemic_

\section{OP0215 TIME-RELATED TRENDS IN OPIOID PURCHASES AMONG PATIENTS WITH EARLY INFLAMMATORY ARTHRITIDES}

P. Muilu ${ }^{1}$, V. Rantalaiho ${ }^{2,3}$, H. Kautiainen ${ }^{4}$, L.J. Virta ${ }^{5}$, K. Puolakka ${ }^{6} .{ }^{1}$ Department of Medicine, Tampere University Hospital; ${ }^{2}$ Centre fo rheumatic diseases, Tampere University Hospital; ${ }^{3}$ Faculty of Medicine and Life sciences, University of Tampere, Tampere; ${ }^{4}$ Department of General Practice and Primary Health Care, University of Helsinki and Helsinki University Hospital, helsinki; ${ }^{5}$ Research Department, Social Insurance Institution of Finland, Turku; ${ }^{6}$ Department of Medicine, South Karelia Central Hospital, Lappeenranta, Finland

Background: Treatment outcomes in inflammatory arthritis (IA) have improved during the past decades; however, pain management remains a great challenge. There has been a concern of overprescription of opioids during recent years.

Objectives: The aim of this study was to explore the frequency of opioid users in patients with newly-onset IA in comparison with the general Finnish population and discover the proportion of long-term opioid users.

Methods: From the nationwide register maintained by the Social Insurance Institution of Finland we collected all incident adult patients with the five most common IAs between 2010-14. For each case, three eligible controls were randomly selected and individually matched according to age, sex, and place of residence. Opioid purchases between 2009-2015 were obtained from the drug prescription register and evaluated one year before and after the index date (decision of special reimbursement for antirheumatic drugs), further dividing the observation time into 3 month periods. Long-term use was defined as opioid purchases at least in three of these periods per year. All opioids from mild to strong were included.

Results: Data on different diagnosis groups are presented in table 1. The proportion of opioid purchasers among IA patients and their controls are shown in figure $1 \mathrm{~A}-\mathrm{E}$. Also, odds ratio for long-term opioid use after the index date is shown in figure $1 \mathrm{~F}$. 